\title{
Ebola: will enlightened self interest spur us to act?
}

\author{
Fiona Godlee editor in chief, The BMJ
}

More than 4400 people are now reported to have died in the Ebola epidemic in west Africa (doi:10.1136/bmj.g6255), and the US Centers for Disease Control has estimated that as many as 1.4 million people may be infected by the end of January. Fatality rates are reported to be around $50 \%$. Health infrastructure in the three worst affected countries was already struggling but is now close to total collapse. The limited ranks of trained healthcare workers have been decimated by disease, exhaustion, and fear. Almost 200 healthcare workers are known to have died.

The head of the charity Médecins Sans Frontières, Joanne Liu, describes the desperate situation in an interview with The BMJ published this week: "Local doctors have been extremely brave, but we are running out of staff" (doi:10.1136/bmj.g6151). And she herself is "running out of words to convey the sense of urgency." She acknowledges that the capacity of rich nations to respond to distant crises has been stretched like never before in recent months. This year MSF has deployed more staff in more countries than ever before.

What we now need are well trained and well equipped boots on the ground. Liu wants to see bioterrorism teams that countries set up after 9/11 to be deployed to fight Ebola. Countries with historical links to the region, mainly the United States and United Kingdom, are sending (or promising) troops to set up treatment centres. This week Andy Johnston and Mark Bailey describe Operation Gritrock, which has just sent British army medics to Sierra Leone to set up a treatment centre for health workers (doi:10.1136/bmj.g6237). But the response of other countries, Liu says, has been slower and hands off. "Everyone is looking for excuses not to deploy because they are so scared," she says.

Perhaps the only real hope for spurring capable countries into action is enlightened self interest. So the fact that the United Nations Security Council has declared the outbreak a threat to international peace and security should help. So too should the now real threat of spread of the disease beyond west Africa. But so far screening at airports is almost the only result (doi:10. 1136/bmj.g6199; doi:10.1136/bmj.g6147). This may be reassuring to travellers and citizens, but our editorialists David
Mabey and colleagues say it is false reassurance and a waste of money (doi:10.1136/bmj.g6202). Previous experience from the severe acute respiratory syndrome (SARS) epidemic should have told us this, they say. Airport screening for SARS in Canada cost \$C17m (£9m; €12m; \$15m) and identified not a single case.

Mabey and colleagues have done the sums for Ebola. With an incubation period of 21 days - and assuming that people who want to make the journey may hide symptoms and signs-screening to prevent people boarding flights is likely to fail, and screening on entry to a country will have "no meaningful effect on the risk of importing Ebola." Far better, they say, to provide clear information to those who may be at risk on how and where to seek care. This would be as effective as screening at a fraction of the cost. In a letter this week Sunday Oluwafemi Oyeyemi and colleagues confirm the need for clear and accurate information on how to prevent and treat Ebola infection (doi:10.1136/bmj.g6178). Their review of information shared on Twitter within affected countries shows a high prevalence of misleading information, some of which, such as the advice to drink salty water, is known to have killed people. Governments should use Twitter to spread correct information and amend misinformation, they say.

Liu and MSF have been the voice of absolute humanitarian ideals. Many health professionals and military personnel will, as individuals, rise to that same level of moral courage. For the rest, enlightened self interest is not so bad and is better than nothing. But let's spend our resources on the right things. Not airport checks but, as Mabey and colleagues conclude, immediate scaling up of our presence in west Africa, building new treatment centres at a rate that outstrips the epidemic. This would not only help the people in affected countries but reduce the risk of the Ebola virus spreading elsewhere.

All The BMJs articles on the Ebola crisis are at bmj.com/ebola

Cite this as: BMJ 2014;349:g6254

๑ BMJ Publishing Group Ltd 2014 